Journal of Patient-Centered

Volume 2

Issue 4 -- Integrative Medicine

Article 33

$11-20-2015$

\title{
Incidence of Breast, Colorectal and Lung Cancers and Mortality Among Women Within Midwestern States
}

Ruth M. Perez

Matthew Rappelt

Kathryn Kossow

Maharaj Singh

Follow this and additional works at: https://aah.org/jpcrr

Part of the Medical Humanities Commons, Oncology Commons, and the Public Health Education and Promotion Commons

\section{Recommended Citation}

Perez RM, Rappelt M, Kossow K, Singh M. Incidence of Breast, Colorectal and Lung Cancers and Mortality Among Women Within Midwestern States. J Patient Cent Res Rev 2015;2:214. http://dx.doi.org/

10.17294/2330-0698.1243

Published quarterly by Midwest-based health system Advocate Aurora Health and indexed in PubMed Central, the Journal of Patient-Centered Research and Reviews (JPCRR) is an open access, peer-reviewed medical journal focused on disseminating scholarly works devoted to improving patient-centered care practices, health outcomes, and the patient experience. 
ACM for two targeted family medicine residency teaching clinics.

Results: Through February 2015, 29 providers systemwide completed the module with 212 in progress. Data from targeted clinics demonstrated system level increases in all metrics over project period, with average increases of $21 \%$ in ACT completion, $34 \%$ in use of AAP and 7\% in ACM use. Participants' evaluations are strong: $80 \%$ of module completers rate MOC training as yielding a high return on their time investment; $100 \%$ of M3 students report completing an ACT test and an associated impact on their patient's care. Participant comments include: “... since completing this project I will strive to screen all my asthma patients at every visit ... [and] adjust their medications based on it. [It's] an extremely useful clinical tool"; and "I plan on trying to use [the] ACT with more appointments as a way to check up on asthma quickly. Score increased to $44 \%$ with minimal intervention."

Conclusion: Aligning physician education opportunities across the continuum with health care system metrics meets board (re)certification requirements, residency and medical student accreditation requirements and improves care for patients.

\section{Incidence of Breast, Colorectal and Lung Cancers and Mortality Among Women Within Midwestern States}

Ruth M. Perez, Matthew Rappelt, Kathryn Kossow, Maharaj Singh

\section{Aurora Research Institute, Aurora Health Care}

Background: Breast, colorectal and lung cancers have been shown to be the most common cancers as well as the leading causes of cancer death among women. Previous studies suggest that the Northeast had significantly higher rates in incidence and mortality than the Midwest, South and Western regions. However, new data indicates that the Midwest now harbors the highest mortality rates. In Wisconsin, the sixth largest state in the Midwest, cancer is the leading cause of death. Differences in incidence and mortality of breast, colorectal and lung cancers have been observed between Wisconsin, other Midwestern states and national data, warranting further investigation.

Purpose: To examine the incidence and mortality of Wisconsin females across breast, colorectal and lung cancers compared to that of the national average along with the individual states that comprise the Midwest (ND, SD, $\mathrm{NE}, \mathrm{KS}, \mathrm{MN}$, IA, MO, IL, IN, OH and MI).

Methods: Female incidence and mortality rates were retrieved from the Centers for Disease Control and Prevention (CDC) National Program of Cancer registries for the 2011 year, while census data was retrieved from the U.S. Census Bureau for the nation, region and individual states. Data was analyzed using two-sample z-test for proportions with significance set at $\mathrm{P}<0.05$.

Results: Compared to the national incidence of breast cancer
(122 per 100,000), Wisconsin women had a significantly higher incidence $(\mathrm{P}<0.05)$. Within the Midwest, Wisconsin had a higher incidence than Indiana $(\mathrm{P}<0.0005)$ as well as higher mortality than Nebraska $(\mathrm{P}<0.05)$. However, Wisconsin had lower incidence of breast cancer than Minnesota and Ohio $(\mathrm{P}<0.01)$ and lower mortality than Ohio $(\mathrm{P}<0.05)$. Wisconsin had both lower incidence and mortality than Illinois, Indiana, Iowa and Nebraska $(\mathrm{P}<0.05)$ for colorectal cancer. For lung cancer, Wisconsin had a higher incidence and mortality than Minnesota and Nebraska $(\mathrm{P}<0.005)$ and lower incidence than Indiana, Michigan and Missouri $(\mathrm{P}<0.05)$. No significant differences were noted between Wisconsin and other Midwestern states.

Conclusion: Though variations exist between Wisconsin and other Midwestern states in incidence and mortality, there are no consistent trends between these states and the three most common cancers. As a whole, however, the Midwest had statistically higher incidence and mortality rates than the nation. Further investigations into the regional differences between Wisconsin, the Midwest, and other states with similar demographic composition will be explored.

\section{Fair Weight Loss After Gastric Rebanding for Slippage}

\section{Ahmed Dalmar, Maharaj Singh, Sara K. Roloff, Thomas Y. Chua}

\section{Aurora Research Institute, Aurora Health Care; Wisconsin Bariatrics}

Background: Laparoscopic adjustable gastric banding (LAGB) is one of the most common bariatric surgery procedures performed in the United States. LAGB results in safe and satisfactory weight loss, but it is often complicated with slippage, a complication requiring rebanding (reoperation). There is a paucity of studies and no uniform consensus regarding weight loss after rebanding.

Purpose: This study assessed the effect of rebanding for slippage after LAGB on weight loss up to five years.

Methods: This is a historical cohort study of 865 patients who underwent LAGB from 2001 to 2011. Rebanding was performed in $103(11.9 \%)$ patients. Primary outcome of interest was percent excess weight loss (\% EWL), which was categorized as fair $(>25-50 \%)$ and failure $(<25 \%$ EWL) after rebanding. Of the 103 patients diagnosed with slippage, 23 were excluded from further analysis because either the band was removed $(n=15)$, or they were rebanded twice due to recurrent slippage $(n=2)$ or lack of enough data $(n=6)$. Of the remaining 80,76 patients were matched with 76 controls without slippage using propensity matching. Paired t-test was used to compare weights (initial, at reoperation, and 1,2, 3, 4 and 5 years before and after rebanding). Chisquare test was used to compare EWL rate between groups. Multivariate logistic regression was performed to determine predictive probability for propensity matching of slippage.

Results: The majority of patients were female $(82.9 \%)$. Mean age was $44.32 \pm 11.3$ years, mean preoperative body 